Mokhtar M.S Al-Hamidi BDS, MSc.

Mariam Noaman Jasim ( Dental GP )

Wurood Jasim Dhayef ( Dental GP)

\section{Bolton's Ratios for Patients with Different Angle's Malocclusions Seeking Orthodontic Treatment in Kurdistan Region}

Tishk International University

Tishk International University

Tishk International University

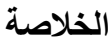

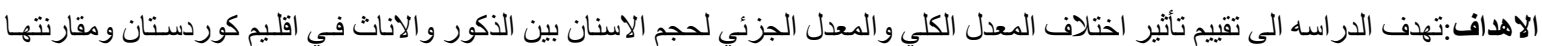

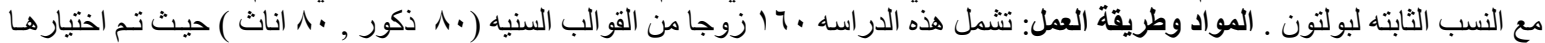

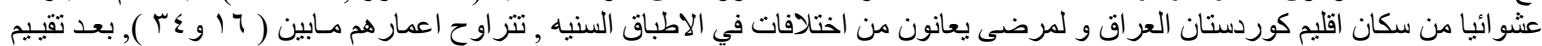

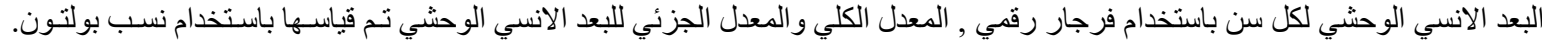

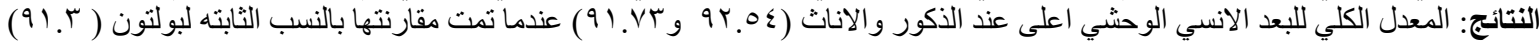

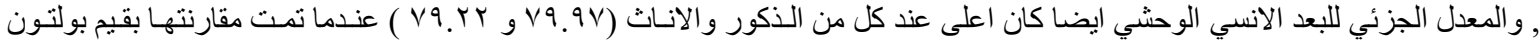

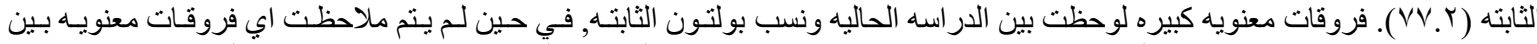

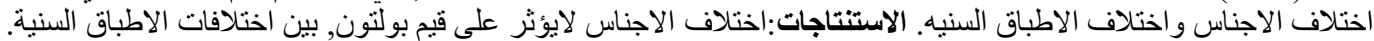

\begin{abstract}
Aims: The study aimed to evaluate the overall and anterior Bolton's ratio between females and males of the Kurdistan population, and then compare it to Bolton's original ratio. Materials and methods: This crosssectional study consisted of 160 orthodontic models ( 80 males, 80 females) that randomly selected from the Kurdistan Iraq population for patients seeking orthodontic treatment, ranging in age from 16 to 34 years. After evaluating the width of each tooth separately using digital caliper, anterior and total ratios were calculated by a formula presented by Bolton. Results: The study's overall Bolton's ratio was significantly higher for both females and males at 92.54 and 91.73, respectively, when compared to that of Bolton's original value of 91.3; the anterior Bolton's ratio was also significantly higher at 79.97 for males \& 79.22 for females, when compared to that of Bolton's original value of 77.2. The high significant difference was observed between the current study and Bolton's ratios, with p-value of 0.01 , whereas no significant gender differences in any malocclusion group have been found. Conclusions: No gender effect on Bolton's ratios among all Angle's classification types.
\end{abstract}

Keywords: Bolton ratios, Tooth size discrepancy, Kurdistan

Al-Hamidi MM., Jasim MN., Dhayef WJ. Bolton's Ratios for Patients with Different Angle's Malocclusions Seeking Orthodontic Treatment in Kurdistan Region. AL-Rafidain Dent J. 2021; 21(2):281-291.

DOI: 10.33899/rden.2021.128919.1066 @2020, College of Dentistry, University of Mosul.

Received: 17/11/2020 Sent to Referees: 21/12/2020

This is an open access article under the CC BY 4.0 license
Accepted for Publication: 28/12/2020 (http://creativecommons.org/licenses/by/4.0/). 


\section{INTRODUCTION}

Delivering an attractive natural smile is a key element in orthodontic patient satisfaction, as teeth master the beauty of the face (esthetic) in addition to speech (phonation) and mastication $(1,2,3)$.

The early prospectors of orthodontics realized the importance of the relation of the teeth in the same and opposite arches should be harmonized in addition to other structures in the face and the mouth, including the tongue, muscles of mastication, and the bones of maxilla and mandible. Spacing and crowding represent the most functional and esthetic problems for patients who attend orthodontic clinics ${ }^{(3,4) \text {. }}$

Since the fundamental goal of the orthodontic procedure is to correct alignment of teeth, the accurate evaluation and analysis of dental crowding and the space required to minimize it is important for the successful prognosis of orthodontic treatment, knowing the amount of crowding would be advantageous in other respects too like public health programs and epidemiological studies. By subtracting the required space from the available space, the degree and amount of spacing and crowding can be calculated ${ }^{(5)}$.

Every orthodontist needs to have an idea about the normal growth of dentition and all changes within the arches with age ${ }^{6}$ and having good knowledge about teeth sizes for good treatment planning and good post-treatment occlusion between maxilla and mandible.
A discrepancy in this ratio can instruct treatment plan as if the re approximation is enough or extraction of specific teeth is required, it could also offer whether to include esthetic procedures such as composite bonding, prosthetic reconstruction, or crown recontouring ${ }^{(7)}$.

Variations in tooth size and width are correlated to ethnic groups ${ }^{(8,9)}$, as in many other attributes, the size of teeth differs from male to female, female teeth usually smaller than male teeth ${ }^{(9)}$.

This study is designed to calculate the overall and anterior Bolton ratios in Angle Class I, II, and III malocclusions, and to look over the correlation between tooth size discrepancies in both males and females in Iraq specifically in Kurdistan.

Therefore, the aim of the study was:

1. To evaluate the anterior and overall Bolton's ratios in Angle Class I, II, and III malocclusions in Kurdistan region

2. To differentiate the obtained anterior and overall Bolton's ratios in Angle Class I, II, and III malocclusions between females and males of the same population

3. To compare the obtained anterior and overall Bolton's ratios in Angle Class I, II, and III malocclusions of the Kurdistan population to Bolton's original ratio. 


\section{MATERIALS AND METHODS}

The present study started by selecting 500 orthodontic models of patients seeking orthodontic treatment at private and governmental clinics in Kurdistan, Specifically in Sulaymaniyah and Erbil cities.

Kurdistan, which is an autonomous region in northern Iraq, is bordered by Iran from the east, Syria from the west, and Turkey from north and Iraq from the south. Erbil is the regional capital of Kurdistan (known as Hewlêr in Kurdish).Sulaymaniyah is another City in Kurdistan which is located in the east not far from the Iran-Iraq border.

Different ethnic groups live in Kurdistan including Kurds, Arabs, and Turkmans, with an estimated population of 5.123 million, the pop- ulation shows an overall gender-balance, revealing an index of 100 males per 100 females ${ }^{10}$.

Data collection started at the same time in both cities from $24^{\text {th }}$ of August till $19^{\text {th }}$ of October, afterward the 500 casts has undergone examination and sorting to meet the inclusion criteria, at which 200 casts didn't match and had been excluded.

Eventually, 160 pre-treatment casts which consisted of (80 males and 80 females) have been randomly selected from the remained 300 casts to have an equal comparison between the two genders. The study group consisted of 23 Class I patients (12 males and 11 females), 107 Class II patients (52 males and 55 females), and 30 Class III (16 males and 14 females) as shown in (Table 1).

Table (1): Sample distribution

\begin{tabular}{lccccc}
\hline \multirow{3}{*}{ Gender } & & Class I & Class II & Class III & Total \\
& Male & $\mathbf{1 2}$ & $\mathbf{5 2}$ & $\mathbf{1 6}$ & $\mathbf{8 0}$ \\
Total & Female & 11 & 55 & 14 & 80 \\
& & $\mathbf{2 3}$ & $\mathbf{1 0 7}$ & $\mathbf{3 0}$ & $\mathbf{1 6 0}$ \\
\hline
\end{tabular}

The inclusion criteria were:

1. Age ranges from 16 to 34 years.

2. Class I, II, III molar and canine relationship.

3. No large interproximal restoration

4. No previous orthodontic treatment.

5. All permanent teeth fully erupted in both jaws from central incisor to the first molar

6. Good quality cast models
7. Absences of attrition, abrasion, and erosion $^{(3)}$

Two examiners performed the measurements starting from the first molar, the greatest interproximal width (from mesial to distal contact point) has been measured by using sliding stainless digital calipers (Markenlos, china) having an accuracy of $0.01 \mathrm{~mm}$ as shown in Figure $1^{(11,12) \text {. }}$ 


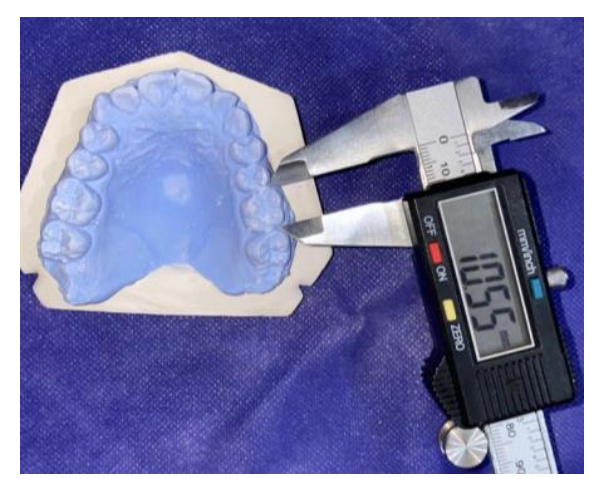

Figure (1): Measurement of mesio-distal width

Next, the calculations of the summations were performed by measurement of the width of the teeth of the maxillary and mandibular arches for total and anterior ratios ${ }^{(13,14)}$.

Then Bolton's overall ratio (first molar to first molar) and anterior ratio (canine to canine) was calculated by using the following formula:

Overall ratio $(\%)=$ Sum of mandibular 12/sum of maxillary 12) $\times 100$

Anterior ratio $(\%)=$ Sum of mandibular anterior teeth/sum of maxillary anterior teeth $\times 100^{(4,}$ 7, 14).

\section{Calibration}

Intra examiner and inter examiner calibration were performed to reduce the possibility of mistakes by randomly selecting 10 cases with different malocclusion types as samples from the 160 casts, the inter examiner made analyses of these cases twice with an interval of 2 weeks. Afterwards, the same samples had been evaluated by intra examiner separately with a period of one week between the two examina- tions. The paired t-test was performed to find the variations between the two results, the readings showed a $p$-value of 0.99 no significant difference.

\section{Statistical analysis}

After the collection and coding of the data, the results were analyzed by windows based SPSS program using t-independent test and ANOVA test with a level of significance at $p \leq 0.05$.

\section{RESULTS}

The statistical t-test analysis in Table 2 shows a gender comparison of overall and anterior ratios of Kurdistan population, the mean value of anterior ratio for males was 79.97 whereas for females was 79.22. The mean value of overall ratio for males was 92.54 whereas for females were 91.73, even though both the values were somewhat more in males than in females, no significant variation was observed between them. Figure 2 shows the graphical comparison of the same result. 
Table (2): Comparison overall and anterior ratios between males and females

\begin{tabular}{cccccc}
\hline \multirow{2}{*}{ Overall Bolton } & Gender & $\mathbf{N}$ & Mean & \pm SD & P-value \\
\cline { 2 - 5 } Anterior Bolton & Male & 80 & 92.54 & \pm 5.74 & 0.30 \\
& Female & 80 & 91.73 & \pm 3.98 & \\
& Male & 80 & 79.97 & \pm 4.85 & 0.32 \\
& Female & 80 & 79.22 & \pm 4.59 & \\
\hline$P>0.05$. N= Number; & SD=Standard deviation
\end{tabular}

$P>0.05 . \mathrm{N}=$ Number; $\mathrm{SD}=$ Standard deviation

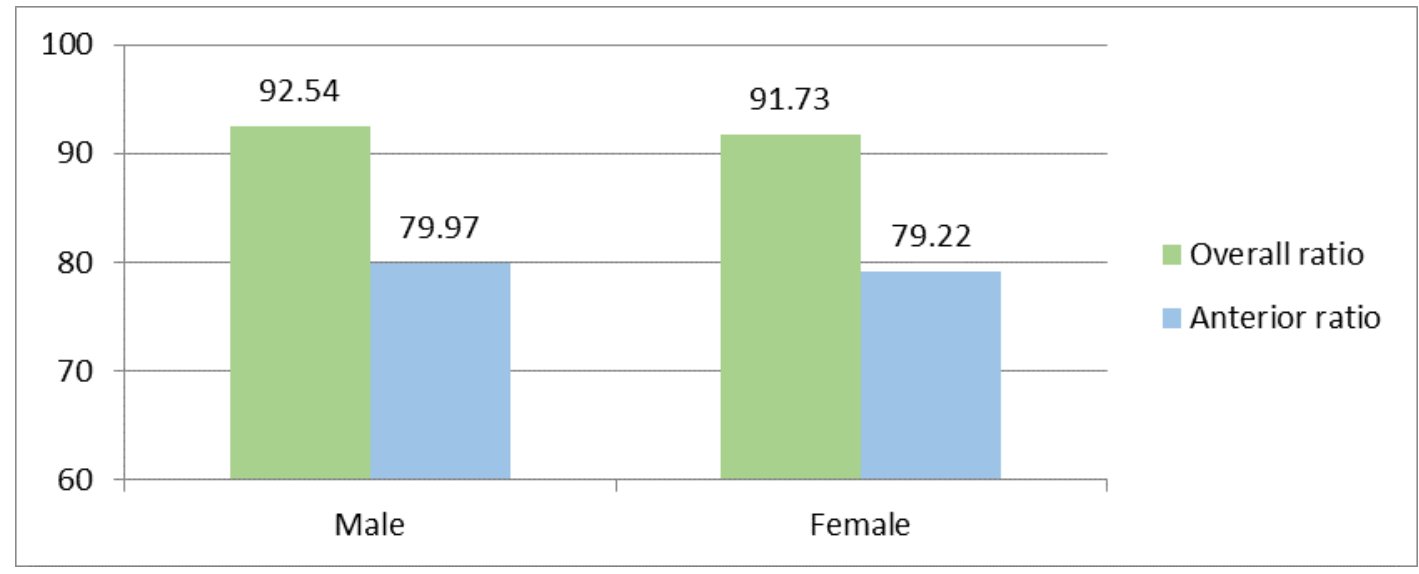

Figure (2): Gender-wise differentiation of the anterior and overall ratios of the study

Table 3 and 4, shows the number of taken cases from each class of malocclusion separately, and the com parison of anterior \& overall ratio in addition to $p$-value using one way ANOVA test.

Table (3): Comparison of Anterior Bolton's ratio among different malocclusion types

\begin{tabular}{lllll}
\hline & N & Mean & P-value & Mini - Maxi \\
\hline Class I & 23 & 91.7857 & 0.84 & $85.70-112.10$ \\
Class II & 107 & 92.3000 & & $84.20-111.50$ \\
Class III & 30 & 91.8200 & & $79.60-109.10$ \\
Total & $\mathbf{1 6 0}$ & $\mathbf{9 2 . 1 3 6 1}$ & & $\mathbf{7 9 . 6 0}-\mathbf{1 1 2 . 1 0}$ \\
\hline
\end{tabular}

Table (4): Comparison of overall Bolton's ratio among different malocclusion types

\begin{tabular}{lllll}
\hline & N & Mean & P-value & Mini - Maxi \\
\hline Class I & 23 & 79.17 & 2.95 & $71.20-89.23$ \\
Class II & 107 & 79.98 & & $66.00-96.14$ \\
Class III & 30 & 78.52 & & $66.80-90.00$ \\
Total & $\mathbf{1 6 0}$ & $\mathbf{7 9 . 5 9}$ & & $\mathbf{6 6 . 0 0}-\mathbf{9 6 . 1 4}$ \\
\hline
\end{tabular}

The statistical t-test analysis in table

$5 \&$ figure 3 show the comparison of ante- rior and overall ratios of females and males separately with that of Bolton's standard ratios. The males as well as fe- 
males $(p \leq 0.01)$ in the study population had significantly higher overall ratio compared to that of Bolton's values. Significant difference $(p \leq 0.01)$ was detected for both genders and among all groups of malocclusion when comparison has been performed between anterior ratio of the study to Bolton's standard ratio.

Table (5): Comparison of Bolton's standard ratio to study population

\begin{tabular}{ccccc}
\hline Ratios & Gender & Population & Bolton's value & P-value \\
\hline Overall Bolton & Male & 92.5 & 91.3 & $\leq 0.01$ \\
& Female & 91.7 & 91.3 & $\leq 0.01$ \\
Anterior Bolton & Male & 79.9 & 77.2 & $\leq 0.01$ \\
& Female & 79.2 & 77.2 & $\leq 0.01$ \\
\hline
\end{tabular}

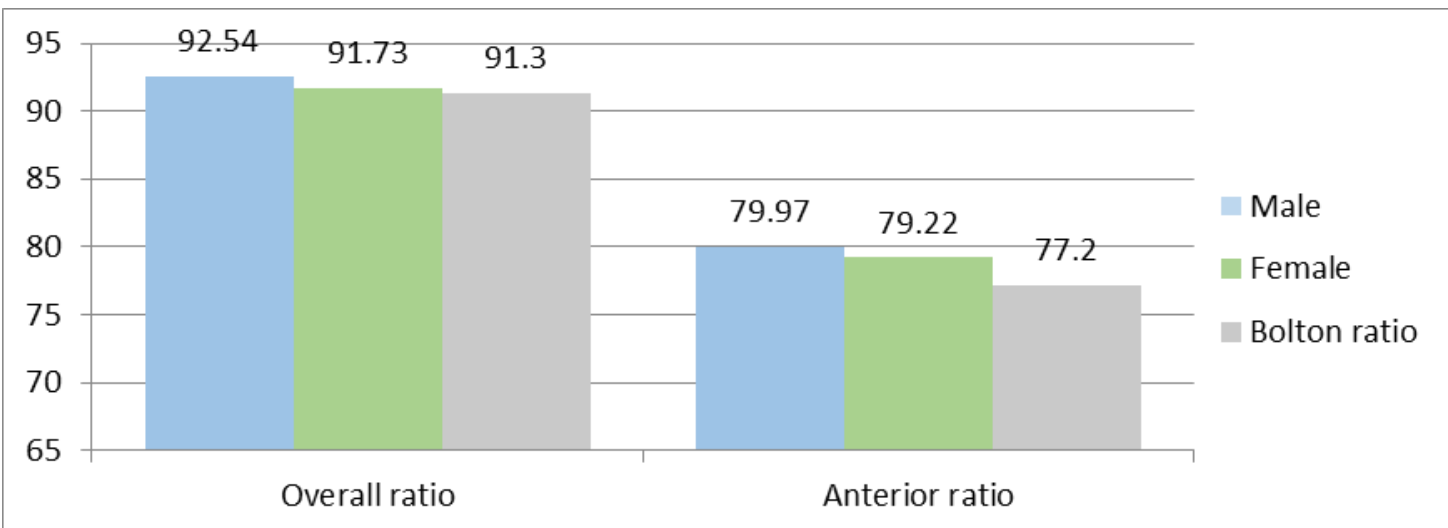

Figure (3): Overall and anterior ratios of females and males of study group compared to Bolton's standard values

Since a non-significant difference was observed in both females and males, the mean value was taken to represent the whole sample. Table 6 shows the comparison using t-test of overall and anterior ratios of Kurdistan population (both male \& female) with the values obtained from Bolton's study. Overall ratio of Kurdistan population showed highly significant at $p \leq 0.01$, i.e., 92.2 ( $p$ $\leq 0.01)$ when compared to standard Bolton's values (91.30). Furthermore, the anterior ratio of Kurdistan population also showed highly significant at $p \leq 0.01$, i.e., $79.6(p \leq 0.01)$ when compared to standard Bolton's values (77.20).

Table( 6): Comparison of total population to Bolton's value

\begin{tabular}{llll}
\hline \multicolumn{1}{c}{ Ratios } & Population & Bolton's value & P-value \\
\hline Overall Bolton & 92.2 & 91.3 & $\leq 0.01$ \\
Anterior Bolton & $\mathbf{7 9 . 6}$ & $\mathbf{7 7 . 2}$ & $\leq \mathbf{0 . 0 1}$ \\
\hline
\end{tabular}




\section{DISCUSSION}

The perception of aesthetics differs from one to another person and is impressed by social environment and personal experiences ${ }^{(15) .}$

Among the various diagnostics tools used in order to achieve perfect occlusion with optimal overbite and overjet, Bolton's tooth size analysis is critically important, and it's considered to be the most reliable and common method for detecting interarch discrepancy ${ }^{(7)}$.

Due to ethnic and gender variations, various studies suggest that Bolton's ratio cannot be universally applied across the populations. In addition, Bolton's ratio can differ in patients with different malocclusions; the original Bolton study was acquired from 55 samples with ideal occlusion, 11 untreated orthodontically \& 44 orthodontically treated ${ }^{(8,7,16)}$.

The Relationship between mandibular and maxillary teeth drew the attention of the examiners over decades due to its importance ${ }^{(2)}$, Initial investigations on tooth size were given by Black (1897) ${ }^{(17)}$ and Neff (1949) ${ }^{(18)}$.Then Bolton presented his anterior and overall ratios by studying 55 model patients having perfect class I occlusions ${ }^{(7,19)}$.

Bolton's analysis studies the interrelation of the mesio-distal width of the maxillary teeth to that of the mandibular teeth, according to Bolton the anterior ratio should be $77.2 \pm 0.22$ per cent and that's obtained by adding the widths of the six anterior lower teeth divided by the sum of the six anterior upper teeth, while overall ratio should be $91.3 \pm 0.26$ per cent calculated by adding the widths of the 12 lower teeth divided by the sum of the widths of the 12 upper teeth ${ }^{(13)}$.

That's why it's very helpful in clinical settings and provides perception into functional and esthetic result of orthodontically treated cases, obliterating the need for a diagnostic set$\operatorname{up}^{(7,20)}$.

In the present study, Bolton's ratio derived by using randomly selected 160 samples of different malocclusions. the data were collected from samples of untreated individuals seeking orthodontic treatment, then the anterior and overall ratios were contrast between two genders, it showed no significant difference in either of them, it might be due to close distribution of the mesiodistal width of teeth in females and males; the result of the present study support the findings done by Jamal. ${ }^{(21)}$ in Tikrit city one of the Iraq cities \& Ta. et al., (22) in Southern Chinese population. Alam et al., ${ }^{(20)}$ conducted their study in different malocclusions also stated that there is no gender variation in the overall and anterior ratios. Nourallah et al., ${ }^{4}$ also obtained the same results concerning the gender difference when he applied the Bolton standards upon the Syrian population, Fattahi et al., ${ }^{(23)}$ studied the Iranian population, although his overall ratio didn't show a significant difference, the anterior ratio showed significant gender variation among classes of malocclusion, therefore its concluded that gender varia- 
tion in tooth size ratios can be population specific and it's not applied to our study population.

The result of the study shows the anterior and overall Bolton ratio through class I, II and III too, where no significant difference had been observed, this result was similar to study done by and Al-Khateeb \& Abu Alhaija ${ }^{24}$, Jabri et al., ${ }^{25}$ in Nanjing, China, Endo et al., ${ }^{26}$ among a Japanese peoples and Basaran et al., ${ }^{27}$ observed no considerable difference for both ratios between the groups of malocclusion, which are in disagreement with the results of Wędrychowska-Szulc et al., ${ }^{13}$ that revealed significant differences of anterior and overall Bolton ratio among malocclusion classes for males and females, Othman and Harradine 28 and Nie and lin ${ }^{29}$ showed the same result.

As there was no considerable difference in overall and anterior ratios between two genders, the ratios were counted as a whole in order to compare it with that of Bolton ${ }^{7}$.

The result of anterior and overall ratios in this study was significantly higher than Bolton's value. Studies conducted by Hashim et al., ${ }^{3}$ in Qatar, Jaiswal and Paudel ${ }^{30}$ in Nepalese population and Subbarao et al., ${ }^{31}$ in Indian population also revealed highly significant at $p \leq 0.01$ for both overall and anterior ratios upon comparison with Bolton's standard values.

In disagreement, Trehan and Sharma 9 ratios were similar to Bolton's values with no significant variance.
Bolton has designed his calculations following the observation that tooth size was important for ideal occlusion; the measurements were based on 55 model patients with perfect malocclusion decades ago (1958) and it consisted of only Caucasian population, after many years of revolutions and changes in life style of people among divergent populations.

New studies indicate that modern postindustrial human populations are more susceptible to dental crowding due to narrowing of the dental arches because of increasing in processing of food, most of these investigations showed that the recent inclination in the rate of malocclusions among populations must be assigned to the availability of a more processed diet that needs less masticatory action, moreover dental crowding can be seen in lower frequencies in some populations which might be an outcome of a homogenous genetic background revealed in a small population ${ }^{32}$.

All these factors in addition to different methods of measuring, Bolton's anterior and overall ratio cannot represent samples from other population and races, after applying Bolton analysis on any sample, high discrepancy will be noticed compared to Bolton ratios which could be the reason for diverse findings.

\section{REFERENCES}

1. Chang CA, Fields Jr HW, Beck FM, Springer NC, Firestone AR, Rosenstiel S, Christensen JC. Smile esthetics from patients' perspectives for faces of varying at- 
tractiveness. $\quad$ AJO-DO. 2011 1;140(4):e171-80.

2. Ala'a Hayder Abdalla Hashim AL, Eldin HM, Hashim HA. Bolton tooth size ratio among Sudanese Population sample: A preliminary study. Journal of orthodontic science. 2015;4(3):77.

3. Hashim HA, Najah AS, Hashim AH. Bolton tooth size ratio among qatari population sample: An odontometric study. Journal of orthodontic science. 2017;6(1):22.

4. Nourallah AW, Splieth CH, Schwahn C, Khurdaji M. Standardizing interarch toothsize harmony in a Syrian population. The Angle Orthodontist. 2005;75(6):996-9.

5. Johal AS, Battagel JM. Dental crowding: a comparison of three methods of assessment. European Journal of orthodontics. 1997 1;19(5):543-51.

6. Patel D, Mehta F, Patel N, Mehta N, Trivedi I, Mehta A. Evaluation of arch width among class I normal occlusion, class II division 1, class II division 2, and class III malocclusion in indian population. Contemporary clinical dentistry. 2015;6(Suppl 1):S202.

7. Sajal KK, Gupta R, Pai V, Desai P, Mishra SK, Hosamani J. Applicability of Bolton's Analysis: A Study on Tibetan Community. APOS Trends in Orthodontics. 2018;8(4):209-12.

8. Bernabe E, Major PW, Flores-Mir C. Tooth-width ratio discrepancies in a sample of
Peruvian adolescents. American Journal of Orthodontics and Dentofacial Orthopedics. 2004 1;125(3):361-5.

9. Trehan M, Agarwal S, Sharma S. Applicability of Bolton's analysis: A Study on Jaipur population. International journal of clinical pediatric dentistry. 2012;5(2):113.

10. Paasche TF, Sidaway JD. Transecting security and space in Kurdistan, Iraq. Environment and Planning A. 2015;47(10):2113-33.

11. Machado LA, Vilella OD, Agostinho LM. Evaluation of two techniques to measure the available space in the mandibular dental arch using the method error. Revista Odonto Ciência. 2012;27(3):228-32.

12. Wermerson, Christopher Paul. "Comparison of tooth widths, arch widths, arch lengths in early mixed and permanent class I normal dentitions to class I and II crowded dentitions." MS (Master of Science) thesis,university of Iowa, 2016; 68-72.

13. Wędrychowska-Szulc B, JaniszewskaOlszowska J, Stepień P. Overall and anterior Bolton ratio in Class I, II, and III orthodontic patients. The European Journal of Orthodontics. 2010 1;32(3):313-8.

14. Kachoei M, Ahangar-Atashi MH, Pourkhamneh S. Bolton's intermaxillary tooth size ratios among Iranian schoolchildren. Med Oral Patol Oral Cir Bucal. 2011 1;16(4):e568-72.

15. Flores-Mir C, Silva E, Barriga MI, Lagravere MO, Major PW. Lay person's 
perception of smile aesthetics in dental and facial views. Journal of orthodontics. 2004;31(3):204-9.

16. Araujo E, Souki M. Bolton anterior tooth size discrepancies among different malocclusion groups. The Angle Orthodontist. 2003;73(3):307-13.

17. Black GV. Descriptive anatomy of the human teeth. SS White Dental Manufacturing Company; 1897.

18. Neff CW. Tailored occlusion with the anterior coefficient. American Journal of Orthodontics and Dentofacial Orthopedics. 1949 1;35(4):309-13.

19. Bolton WA. The clinical application of a tooth-size analysis. American Journal of Orthodontics. 1962 1;48(7):504-29.

20. Alam MK, Hossain MR, Islam MA. Reliability of Bolton tooth size discrepancies in Bangladeshi population. International Medical Journal. 2013 1;20(2):229-31.

21. Jamal KM. Bolton Ratio in Different Groups of Malocclusions in Iraqi Population. Tikrit Journal for Dental Sciences. 2017 16;5(1):19-24.

22. Ta TA, Ling JY, Hägg U. Tooth-size discrepancies among different occlusion groups of southern Chinese children. American Journal of Orthodontics and Dentofacial Orthopedics. 2001 1;120(5):556-8.

23. Fattahi HR, Pakshir HR, Hedayati Z. Comparison of tooth size discrepancies among different malocclusion groups. The European Journal of Orthodontics. 2006 1;28(5):491-5.

24. Al-Khateeb SN, Abu Alhaija ES. Tooth size discrepancies and arch parameters among different malocclusions in a Jordanian sample. The Angle Orthodontist. 2006;76(3):459-65.

25. Jabri MA, Wu S, Zhang Y, Ma J, Wang L. A Review on Comparison of Tooth Size Discrepancies among Angle's Class I, II, and III Malocclusion: Is There a Significance?. The Journal of Contemporary Dental Practice. 2019 1;20(8):994-9.

26. Endo T, Abe R, Kuroki H, Oka K, Shimooka S. Tooth size discrepancies among different malocclusions in a Japanese orthodontic population. The Angle Orthodontist. 2008;78(6):994-9.

27. Basaran G, Selek M, Hamamcı O, Akkuş Z. Intermaxillary Bolton tooth size discrepancies among different malocclusion groups. The Angle Orthodontist. 2006;76(1):26-30.

28. Othman SA, Harradine NW. Tooth-size discrepancy and Bolton's ratios: a literature review. Journal of orthodontics. 2006;33(1):45-51.

29. Nie Q, Lin J. Comparison of intermaxillary tooth size discrepancies among different malocclusion groups. American Journal of Orthodontics and Dentofacial Orthopedics. 1999 1;116(5):539-44. 
30. Jaiswal AK, Paudel KR. Applicability of Bolton's tooth size ratio for Nepalese population. J Nepal Dent Assoc. 2009;10(2):84-7.

31. Subbarao VV, Regalla RR, Santi V, Anita G, Kattimani VS. Interarch tooth size relationship of Indian population: does Bolton's analysis apply?. The journal of contemporary dental practice. 2014 1;15(1):103-7.
32. Normando D, Almeida MA, Quintão CC. Dental crowding: the role of genetics and tooth wear. The Angle Orthodontist. 2013;83(1):10-5 